Counsellia: Jurnal Bimbingan dan Konseling, 9 (1), $2019 \mid 14$ - 26

Copyright (C2019 Universitas PGRI Madiun

ISSN: 2088-3072 (Print) / 2477-5886 (Online)

Available online at: http://e-journal.unipma.ac.id/index.php/JBK

DOI: $10.25273 /$ counsellia.v9i1.3416

\title{
Perbedaan self-regulated learning siswa SMP di Yogyakarta berdasarkan keberadaan kedua orang tua
}

\author{
Irvan Budhi Handaka ${ }^{1}$, Wahyu N. E. Saputra ${ }^{2}$, Said Alhadi ${ }^{3}$. \\ ${ }^{1}$ FKIP, Universitas Ahmad Dahlan, Yogyakarta \\ irvan.handaka@bk.uad.ac.id \\ ${ }^{2}$ FKIP, Universitas Ahmad Dahlan, Yogyakarta \\ wahyu.saputra@bk.uad.ac.id \\ ${ }^{3}$ FKIP, Universitas Ahmad Dahlan, Yogyakarta \\ said.alhadi@bk.uad.ac.id
}

\begin{abstract}
Abstrak
Tujuan penelitian ini adalah untuk menggambarkan komparasi tingkat self-regulated learning siswa yang tinggal bersama kedua orang tuanya dengan siswa yang tinggal jauh dari kedua orang tuanya. Sampel dalam penelitian ini sebanyak 402 siswa SMP di Yogyakarta yang diambil secara stratified random sampling. Komposisi sampel penelitian terdiri dari 150 siswa tinggal jauh dari orang tuanya dan 252 siswa tinggal bersama kedua orang tuanya. Alat ukur yang digunakan untuk mengukur tingkat selfregulated learning adalah skala self-regulated learning. Penelitian ini menggunakan Independent Sample T-Test sebagai teknik analisis datanya. Hasil penelitian menyimpulkan bahwa siswa yang tinggal dengan kedua orang tuanya memiliki tingkat self-regulated learning cenderung sama dengan siswa yang tinggal jauh dari kedua orang tuanya. Hasil penelitian ini merekomendasikan dilakukan identifikasi penyebab tidak adanya perbedaan self-regulated learning pada siswa yang tinggal bersama orang tuanya dengan siswa yang tinggal jauh dari orang tuanya.
\end{abstract}

Kata kunci: self-regulated learning, orang tua

\begin{abstract}
The purpose of this study is to describe the comparability of the level of self-regulated learning of students who live with their parents with students who live far from their parents. The sample in this study were 402 junior high school students in Yogyakarta taken by stratified random sampling. The composition of the study sample consisted of 150 students living far from their parents and 252 students living with their parents. The measuring instrument used to measure the level of self-regulated learning is the scale of self-regulated learning. This study uses the Independent Sample T-Test as a data analysis technique. The results of the study concluded that students who live with both parents have a level of self-regulated learning tend to be the same as students who live far from their parents. The results of this study recommend identification of the causes of the absence of differences in self-regulated learning in students who live with their parents with students who live far from their parents.
\end{abstract}

Keyword: self-regulated learning, parents 


\section{PENDAHULUAN}

Setiap siswa memiliki keinginan untuk bisa meraih prestasi yang optimal. Pencapaian ini merupakan salah satu indikator siswa memperoleh kesuksesan akademik (Froiland, Oros, Smith, \& Hirchert, 2012). Kesuksesan akademik itu sendiri menjadi suatu kebutuhan yang ingin dipenuhi oleh setiap siswa (Freitas \& Leonard, 2011). Ketika siswa mampu untuk mencapai prestasi akademik yang ditargetkan, maka akan mendorong munculnya kepuasan dan kenikmatan siswa dalam menjalani proses belajar. Hal ini tentunya akan memacu siswa untuk kembali mengulang perilakunya dan cenderung berupaya lebih untuk mencapai prestasi akademik yang lebih baik lagi (Carrillo-de-la-Peña \& Perez, 2012).

Siswa perlu memiliki keterampilan tertentu agar mereka mampu meraih prestasi akademik yang optimal, salah satunya adalah self-regulated learning. Siswa yang memiliki kemampuan self-regulated learning yang baik, maka akan menunjang perolehan prestasi belajar yang baik (Broadbent \& Poon, 2015; Caprara et al., 2008; Kosnin, 2007; Latipah, 2010; Zimmerman, 1990, 2013; Zimmerman \& Schunk, 1989, 1989). Data-data dari hasil penelitian tersebut menjadi data penting bagi pihak-pihak terkait di sekolah untuk menyusun program peningkatan prestasi akademik dengan memperhatikan kemampuan self- regulated learning siswa. Konselor menjadi pihak yang memiliki potensi untuk menggarap bidang ini dengan mengimplementasikan pelayanan bimbingan dan konseling.

Kemampuan self-regulated learning siswa terdiri dari beberapa komponen, diantaranya adalah metakognisi, perilaku dan motivasi (Zimmerman \& Schunk, 1989). Ketiga komponen tersebut saling berinteraksi dan terlibat dalam proses belajar siswa. Berdasarkan konsep yang terpaparkan di atas, dapat dipahami bahwa self-regulated learning menjadi sebuah upaya dari diri siswa untuk proaktif dan mandiri dalam menjalani proses belajarnya dengan cara meregulasi dan mengontrol kognisinya, memunculkan motivasi intrinsik untuk belajar, dan melakukan tindakan belajar yang diorientasikan untuk mencapai tujuan belajarnya.

Terdapat empat asumsi umum mengenai self-regulated learning. Pertama, self-regulated learning adalah kegiatan yang aktif serta konstruktif. Asumsi yang pertama ini siswa aktif dalam mencipta dan membangun proses belajar yang optimnal, baik dalam hal upaya memahami, mencapai tujuan, serta memanfaatkan strategi dari informasi yang sudah ada di lingkungan dan alam pikiran siswa itu sendiri. Kedua, siswa memiliki potensi untuk sanggup mengendalikan. Potensi siswa ini meliputi berbagai komponen antara lain melakukan monitoring, 
mengontrol, dan mengatur proses kognitif, motivasi, dan perilaku yang selaras dengan kondisi lingkungan tempat mereka tinggal. Ketiga, siswa memiliki tujuan dan standar belajar yang ingin dicapai. Asumsi ketiga ini dimanfaatkan siswa untuk melakukan penilaian apakah proses belajar efektif untuk dilanjutkan atau perlu melakukan perbaikan karena pencapaian hasil belajarnya yang kurang sesuai dengan standar. Keempat, aktivitas self regulation. Keempat asumsi di atas adalah mediator antara diri personal dengan prestasi dan performa akademik yang diperoleh siswa (Wolters, Pintrich, \& Karabenick, 2005).

Pentingnya self-regulated learning tidak sepenuhnya dapat dimiliki oleh siswa. Berbagai permasalahan kemampuan selfregulated learning masih menjadi perhatian banyak pihak untuk mengentaskannya. Terdapat setidaknya $54,2 \%$ siswa memiliki kategori tingkat self-regulated learning rendah pada siswa salah satu SMA akselerasi di kota Malang.

Penelitian lain juga menggambarkan bahwa siswa yang tidak memiliki self-regulated learning, mereka kurang memiliki rencana belajar yang baik, strategi belajar yang buruk, motivasi belajar yang relatif rendah, dan enggan memaksimalkan segala potensi yang dimilikinya (Savira \& Suharsono, 2013). Selain itu, ditemukan siswa yang hanya melakukan kegiatan sekolah tanpa sambil bekerja memiliki tingkat self-regulated learning yang lebih tinggi daripada siswa yang bersekolah sambil bekerja. Banyak aktifitas belajar yang tersita ketika siswa harus bekerja untuk memenuhi kebutuhan hidupnya (Daulay \& Rola, 2009).

Berbagai penyebab rendahnya self-regulated learning beraneka ragam, akan tetapi salah satu yang dapat memprediksi ini adalah keberadaan orang tua. Siswa yang memiliki dukungan sosial dari keluarganya cenderung dapat memaksimalkan keterampilan selfregulated learning dalam menunjang kegiatan belajarnya (Adicondro \& Purnamasari, 2012). Berbagai bentuk dari dukungan dari keluarga akan memberikan penguat bagi siswa untuk memaksimalkan self-regulated learning.

Berbagai pemaparan dan penggambaran data di atas, menjadi sebuah stimulus untuk melakukan penelitian yang bertujuan untuk mengidentifikasi komparasi tingkat self-regulated learning siswa yang tinggal bersama kedua orang tuanya dengan siswa yang tinggal jauh dari kedua orang tuanya di SMP kota Yogyakarta. Komparasi ini akan memberikan bagaimana karakteristik masing-masing siswa dalam menyikapi self-regulated learning yang ada pada dirinya. Output utama yang diharapkan pada penelitian ini adalah menjadi stimulus bagi konselor untuk merancang program 
layanan bimbingan dan konseling yang berguna untuk mengembangkan self-regulated learning.

\section{METODE PENELITIAN}

Penelitian ini menggunakan rancangan penelitian komparatif. Tujuan dari penelitian ini adalah mencari perbandingan self-regulated learning pada siswa yang tinggal bersama kedua orang tuanya dengan siswa jauh dari kedua orang tuanya. Penelitian ini dilakukan di SMP kota Yogyakarta.

Populasi yang terlibat dalam penelitian ini adalah siswa kelas VIII SMP di Kota Yogyakarta. Sedangkan sampelnya sebanyak 402 siswa yang diambil dengan menggunakan stratified random sampling, 150 siswa yang tinggal jauh dari orang tua dan 252 siswa yang tinggal bersama kedua orang tuanya. Sampel yang diambil diharapkan dapat mewakili populasi sehingga hasil penelitiannya dapat digeneralisasikan pada populasi.

Penelitian ini menggunakan skala self-regulated learning untuk menggali data tingkat self-regulated learning siswa. Skala self-regulated learning terdiri dari dari 43 item pernyataan. Instrumen ini dikembangkan dengan menggunakan akar teori self-regulated learning yang terdiri dari tiga komponen, yaitu metakognisi, motivasi, dan perilaku (B. Zimmerman \& Schunk, 1989).

Pertanyaan penelitian ini akan dijawab menggunakan teknik analisis data Independent Sample T-Test. Teknik analisis data ini dianalisis dengan bantuan program SPSS 20.00. Temuan dari analisis data ini adalah perbandingan self-regulated learning siswa yang tinggal bersama kedua orang tua dan siswa yang tinggal jauh dari orang tua.

\section{HASIL DAN PEMBAHASAN}

Berdasarkan analisis data dengan menggunakan independent sample ttest didapatkan kesimpulan bahwa tidak terdapat perbedaan yang signifikan tingkat self-regulated learning siswa yang tinggal bersama kedua orang tuanya dengan siswa yang tinggal berjauhan dengan kedua orangnya pada SMP di Kota Yogyakarta. Uji beda dengan menggunakan independent sample ttest menggunakan dua asumsi, yaitu uji normalitas dan homogenitas.

Hasil uji normalitas dengan metode Shapiro-Wilk didapatkan hasil sebagai berikut:

Tabel 1 Uji Normalitas

Tests of Normality

\begin{tabular}{llrcc}
\hline \multirow{2}{*}{ KondisiTinggal } & \multicolumn{3}{c}{ Shapiro-Wilk } \\
& Statistic & df & \multicolumn{1}{c}{ Sig. } \\
\hline \multirow{2}{*}{ SkorSRL } & Tinggal jauh dari orang tua & .991 & 150 & .235 \\
& Tinggal bersama orang tua & .994 & 252 & .227 \\
\hline
\end{tabular}


Tabel 1 di atas dapat diinterpretasikan bahwa siswa yang tinggal bersama orang tua nilai signifikansinya adalah 0,235 dan siswa yang tinggal jauh dari orang tua nilai signifikansinya adalah 0,227 . Nilai koefisien ini lebih dari dari 0,05. Sehingga dapat disimpulkan bahwa data skor selfregulated learning memiliki distribusi normal.

Uji asumsi yang kedua adalah uji homogenitas yang bertujuan untuk membuktikan bahwa datanya homogen. Hasil perhitungan SPSS didapatkan hasil sebagai berikut:

Tabel 2 Uji Homogenitas

Test of Homogeneity of Variances

\begin{tabular}{|c|c|c|c|}
\hline \multicolumn{4}{|c|}{ SkorSRL } \\
\hline Levene Statistic & df1 & df2 & Sig. \\
\hline .276 & 1 & 402 & .586 \\
\hline
\end{tabular}

Tabel 2 di atas dapat diinterpretasikan bahwa nilai signifikansi variabel self-regulated learning berdasarkan variabel siswa yang tinggal bersama orang tua dan siswa yang tinggal jauh dari orang tua sebesar 0,276. Jika dibandingkan dengan tingkat kesalahan sebesar 0,05 , maka nilai signifikansinya lebih besar dari 0,05. Sehingga dapat disimpulkan bahwa bahwa data skor self-regulated learning adalah homogen.

Dua pengujian asumsi independent sample t-test, baik uji normalitas dan homogenitas telah terpenuhi. Sehingga dapat dilakukan uji independent sample t-test. Berdasarkan penghitungan dengan menggunakan SPSS, maka didapatkan output sebagai berikut:

Tabel 3 Uji Independent Sample T-Test

\begin{tabular}{|c|c|c|c|c|c|c|}
\hline \multicolumn{7}{|c|}{ Independent Samples Test } \\
\hline & & \multicolumn{2}{|c|}{$\begin{array}{c}\text { Levene's Test } \\
\text { for Equality of } \\
\text { Variances } \\
\end{array}$} & \multicolumn{3}{|c|}{ t-test for Equality of Means } \\
\hline & & $\mathrm{F}$ & Sig. & $\mathrm{t}$ & df & $\begin{array}{l}\text { Sig. (2- } \\
\text { tailed) }\end{array}$ \\
\hline \multirow[t]{2}{*}{ SkorSRL } & $\begin{array}{ll}\text { Equal } & \text { variances } \\
\text { assumed } & \end{array}$ & .296 & .586 & 1.258 & 402 & .119 \\
\hline & $\begin{array}{l}\text { Equal variances not } \\
\text { assumed }\end{array}$ & & & 1.279 & 302.195 & .202 \\
\hline
\end{tabular}

Berdasarkan output independent sample t-test dengan menggunakan SPSS diketahui bahwa nilai signifikansi sebesar 0,119 . Nilai signifikansi tersebut lebih besar dari
0,05. Artinya tidak ada perbedaan rata-rata skor self-regulated learning siswa SMP yang tinggal dengan kedua orang tuanya dengan siswa 
siswa yang tinggal jauh dari kedua orang tuanya.

Keberadaan orang tua dalam mendampingi siswa dalam proses belajar ternyata tidak memiliki dampak signifikan terhadap tingkat self-regulated learning siswa SMP. Temuan penelitian ini menjadi hal dan kajian baru yang dapat menjadi dasar para pemangku kepentingan untuk mengambil sikap dan menentukan strategi intervensi yang tepat dalam mengembangkan selfregulated learning siswa SMP. Konselor menjadi tenaga profesional yang paling tepat untuk membantu siswa dalam mengembangkan selfregulated learning siswa dan berorientasi pada unsur dari dalam diri siswa untuk pengembangan selfregulated learning.

Penelitian ini memiliki kesamaan dengan penelitian terdahulu yang menyimpulkan bahwa tidak ada perbedaan signifikan tingkat self-regulated learning siswa yang tinggal bersama dengan orang tuanya dan siswa yang tinggal jauh dari kedua orang tuanya (Saputra, Handaka, \& Sari, 2019). Penelitian tersebut memiliki kesamaan tempat pelaksanaan dan teknik pengambilan sampelnya, yaitu di Yogyakarta dengan cluster random sampling. Akan tetapi penelitian tersebut dilakukan di tingkat SMK, sedangkan penelitian ini dilakukan di tingkat SMP.

Terdapat juga hasil penelitian terdahulu yang memiliki perbedaan dan cenderung terbalik dengan hasil penelitian ini. Siswa yang mendapatkan dukungan sosial dari keluarganya memiliki self-regulated learning yang lebih baik dibandingkan dengan siswa yang tidak mendapat dukungan sosial dari keluarganya (Adicondro \& Purnamasari, 2012). Hasil penelitian tersebut menjadi berbeda dengan penelitian ini karena pada penelitian tersebut lebih mengidentifikasi tingkat self-regulated learning siswa yang mendapat berbagai bentuk dukungan dari orang tua, baik dalam bentuk pendampingan, motivasi, maupun pengawasan. Dukungan tersebut dapat mendorong siswa untuk memaksimalkan self-regulated learning yang dapat mengantarkannya pada pencapaian prestasi belajar yang maksimal.

Penelitian tentang dukungan sosial keluarga juga dilakukan oleh peneliti lain. Hasil penelitian tersebut menyimpulkan bahwa dukungan sosial yang diberikan oleh keluarga memiliki keterkaitan signifikan terhadap tinggi dan rendahnya tingkat kemandirian belajar siswa (Rambe, 2010). Hal tersebut memiliki makna bahwa tingginya tingkat dukungan sosial yang diberikan orang tua, maka akan berdampak pada tingginya tingkat kemandirian belajar yang ditunjukkan oleh siswa. Sebaliknya, rendahnya tingkat dukungan sosial yang diberikan oleh orang tua, maka akan berdampak pada rendahnya tingkat kemandirian belajar siswa. 
Terdapat juga temuan penelitian lain menyimpulkan bahwa manajemen diri siswa SMK dalam mempersiapkan diri salah satunya dipengaruhi oleh dukungan dari orang tuanya (Baiti \& Munadi, 2014). Akan tetapi, penelitian tersebut tidak mengarah pada identifikasi self-regulated learning tetapi pada kesiapan kerja. Dukungan orang tua penting bagi siswa karena dapat menguatkan siswa untuk beraktualisasi diri dalam melakukan tindakan tertentu.

Kaitan dengan penelitian dukungan sosial keluarga tampak bahwa keberadaan orang tua ternyata tidak cukup untuk berkembangnya tingkat self-regulated learning. Keberadaan orang tua perlu didukung aspek lain agar tingkat selfregulated learning siswa ini mampu berkembang. Salah satu aspek yang mendukung keberadaan orang tua dalam perkembangan tingkat selfregulated learning siswa adalah dukungan yang diberikan secara penuh bagi anaknya.

Penelitian yang dilakukan di Cina menyimpulkan bahwa tinggi atau rendahnya self-regulated learning siswa dipengaruhi oleh gaya pengasuhan yang diterapkan oleh kedua orang tua (Huang \& Prochner, 2003). Siswa yang masuk kategori tinggi tingkat self-regulated learningnya cenderung diasuh oleh orang tua dengan gaya pengasuhan otoritatif, sedangkan siswa yang rendah tingkat self-regulated learning cenderung diasuh oleh orang tua dengan gaya pengasuhan otoriter. Selain itu, pada penelitian tersebut juga menemukan bahwa pola pengasuhan permisif berpengaruh pada tingkat self-regulated learning, walaupun pengaruhnya tidak signifikan. Akan tetapi, penelitian tersebut lebih menekankan pada identifikasi gaya pengasuhan terhadap tingkat self-regulated learning, sedangkan penelitian ini menekankan pada keberadaan orang tua terhadap tinggi rendahnya tingkat selfregulated learning.

Pada zaman revolusi industri 4.0 ini terjadi pergeseran luar biasa. Orang tua yang keberadaannya ada di samping anaknya tetapi mereka cenderung "membiarkan" anak tanpa pengawasan dan cenderung melakukan aktifitas lain. Hal ini tentunya menjadi stimulus munculnya berbagai permasalahan siswa yang mana permasalahan tersebut tidak jarang di luar jangkauan orang tua. Orang tua mengetahui anaknya memiliki masalah ketika sudah dirasakan dampak negatifnya. Sebagai contoh nyata, siswa yang sering bertindak kekerasan kepada teman lainnya. Ketika orang tua dipanggil ke sekolah dan membagikan berbagai tingkah laku maladaptif siswa di sekolah, orang tua baru menyadari dan mengetahui tingkah laku anaknya di sekolah.

Orang tua yang mengalami kegagalan dalam berperan bagi pencapaian akademik siswa menjadi 
bukti tidak mampunya orang tua melatih tanggung jawab siswa sebagai seorang pelajar. Seharusnya orang tua perlu memberikan pengasuhan dan pelatihan agar siswa dapat mempertanggungjawabkan apa saja yang telah dilakukan siswa (Gordon, 1999). Kondisi ini berdampak pada tidak munculnya perasaan tanggung jawab siswa untuk belajar secara mandiri. Belajar secara mansiri ini yang akan mendorong siswa pada keberhasilan akademik.

Hal ini berbanding terbalik dengan yang seharusnya orang tua lakukan, yaitu orang tua melakukan upaya pengasuhan yang tepat untuk keberhasilan anaknya (Graha, 2013). Orang tua yang terlibat secara mendalam pada segala aktifitas yang dilakukan anak dapat memberikan dorongan yang signifikan terhadap perkembangan anak secara optimal (Finn, 1998). Berdasarkan beberapa fakta di atas, dapat dipahami bahwa dukungan yang diberikan oleh kedua orang tuanya perlu dirasakan oleh siswa, yang akan menjadi stimulus bagi siswa untuk terus mengulang perilaku adaptif yang berdampak positif terhadap peningkatan prestasi belajar.

Orang tua memiliki kewajiban untuk dapat berperan dalam menunjang dan mendorong anakanaknya mencapai keberhasilan belajar, termasuk di dalamnya adalah memberikan dorongan penuh pada anaknya untuk dapat mengoptimalkan self-regulated learning, yang mana kemampuan ini yang akan memandu siswa mencapai prestasi akademik yang ditargetkan (Fan \& Chen, 2001; Stewart, 2008). Orang tua dapat mewujudkan tanggung jawab ini dengan cara melakukan pembimbingan terhadap anak terhadap proses belajar mandiri yang dilakukan anak di rumah sesuai dengan program yang telah dibangun di sekolah. Orang tua juga dapat memberikan pengawasan yang ideal bagi anak dalam proses belajarnya di rumah yang diharapkan dapat menunjang pencapaian hasil belajar di sekolah (Umar, 2015). Selain itu, orang tua juga dapat memberikan dukungan bagi perkembangan literasi anak (Antasari, 2016).

Tidak sedikit orang tua yang melupakan perannya dalam mendampingi anaknya untuk dapat beraktualisasi diri dalam hal akademik. Sebagai buktinya muncul berbagai macam kenakalan remaja sebagai akibat maraknya perceraian orang tuanya (Harsanti \& Verasari, 2013). Selain itu, penerimaan diri dan harga diri yang rendah juga terjadi pada anak pasca orang tuanya bercerai (Wangge \& Hartini, 2013). Kasus-kasus di atas menunjukkan bahwa peran orang tua menjadi urgen bagi perkembangan siswa yang maksimal. 


\section{SIMPULAN}

Hasil penelitian yang dilakukan di SMP kota Yogyakarta menyimpulkan bahwa siswa yang tinggal dengan orang tuanya memiliki tingkat self-regulated learning yang sama dengan siswa yang tinggal jauh dari kedua orang tuanya. Hal ini yang menjadi pergeseran di bidang pengasuhan anak bahwa keberadaan orang tua saja tidak cukup untuk perkembangan anak, tetapi keberadaan orang tua perlu ditunjang dengan berbagai bentuk dukungan yang perlu diberikan orang tua untuk perkembangan anaknya secara optimal. Temuan penelitian ini seyogyanya menjadi dasar bagi konselor sekolah untuk memperhatikan variabel keberadaan orang tua dalam membantu siswa mengembangkan self-regulated learning. Penelitian selanjutnya seyogyanya juga dilakukan untuk mengidentifikasi penyebab tidak adanya perbedaan self-regulated learning pada siswa yang tinggal bersama orang tuanya dengan siswa yang tinggal jauh dari orang tuanya.

\section{DAFTAR PUSTAKA}

Adicondro, N., \& Purnamasari, A. (2012). Efikasi diri, dukungan sosial keluarga dan self regulated learning pada siswa kelas VIII. HUMANITAS: Indonesian
Psychological Journal, 8(1), 17-27.

Antasari, I. W. (2016). Dukungan orang tua dalam membangun literasi anak. Edulib, 6(2).

Baiti, A. A., \& Munadi, S. (2014). Pengaruh Pengalaman Praktik, Prestasi Belajar Dasar Kejuruan dan Dukungan Orang Tua Terhadap Kesiapan Kerja Siswa SMK. Jurnal Pendidikan Vokasi, 4(2).

Bangun, D. (2008). Hubungan persepsi siswa tentang perhatian orang tua, kelengkapan fasilitas belajar, dan penggunaan waktu belajar di rumah dengan prestasi belajar ekonomi. Jurnal Ekonomi \& Pendidikan, 5(1).

Broadbent, J., \& Poon, W. L. (2015). Self-regulated learning strategies \& academic achievement in online higher education learning environments: A systematic review. The Internet and Higher Education, 27, 1-13.

Caprara, G. V., Fida, R., Vecchione, M., Del Bove, G., Vecchio, G. M., Barbaranelli, C., \& Bandura, A. (2008). Longitudinal analysis of the role of perceived self-efficacy for self-regulated learning in academic continuance and achievement. Journal of Educational Psychology, 100(3), 525.

Carrillo-de-la-Peña, M. T., \& Perez, J. (2012). Continuous assessment improved academic achievement and satisfaction of psychology 
students in Spain. Teaching of Psychology, 39(1), 45-47.

Daulay, S. F., \& Rola, F. (2009). Perbedaan self regulated learning antara mahasiswa yang bekerja dan yang tidak bekerja. Fakultas Psikologi. Universitas Sumatera Utara.

Fan, X., \& Chen, M. (2001). Parental involvement and students' academic achievement: A metaanalysis. Educational Psychology Review, 13(1), 122.

Finn, J. D. (1998). Parental engagement that makes a difference. Educational Leadership, 55(8), 20-24.

Freitas, F. A., \& Leonard, L. J. (2011). Maslow's hierarchy of needs and student academic success. Teaching and Learning in Nursing, 6(1), 9-13.

Froiland, J. M., Oros, E., Smith, L., \& Hirchert, T. (2012). Intrinsic motivation to learn: The nexus between psychological health and academic success. Contemporary School Psychology: Formerly" The California School Psychologist", 16(1), 91100.

Gordon, T. (1999). Menjadi orang tua efektif: petunjuk terbaru mendidik anak yang bertanggung jawab. PT Gramedia Pustaka Utama.

Graha, C. (2013). Keberhasilan anak tergantung orang tua. Elex Media Komputindo.

Harsanti, I., \& Verasari, D. G. (2013). Kenakalan pada remaja yang mengalami perceraian orang tua. Prosiding PESAT, 5.

Huang, J., \& Prochner, L. (2003). Chinese parenting styles and children's self-regulated learning. Journal of Research in Childhood Education, 18(3), 227-238.

Kosnin, A. M. (2007). Self-regulated learning and academic achievement in Malaysian undergraduates. International Education Journal, 8(1), 221228.

Latipah, E. (2010). Strategi self regulated learning dan prestasi belajar: kajian meta analisis. Jurnal Psikologi, 37(1), 110-129.

Rambe, A. R. R. (2010). Korelasi Antara Dukungan Sosial Orang Tua dan Self-Directed Learning pada Siswa SMA. Jurnal Psikologi, 37(2), 216223.

Saputra, W. N. E., Handaka, I. B., \& Sari, D. K. (2019). SelfRegulated Learning Siswa SMK Muhammadiyah di Kota Yogyakarta: Kedua Orang Tua Berpengaruhkan? Jurnal Pendidikan (Teori Dan Praktik), 4(1), 7-11.

Savira, F., \& Suharsono, Y. (2013). Self-Regulated Learning (SRL) dengan Prokrastnasi Akademik pada Siswa Akselerasi. Jurnal Ilmiah Psikologi Terapan, 1(1), 6675.

Stewart, E. B. (2008). School structural characteristics, student effort, peer associations, and parental involvement: The influence of 
school-and individual-level factors on academic achievement. Education and Urban Society, 40(2), 179204.

Umar, M. (2015). Peranan orang tua dalam peningkatan prestasi belajar anak. JURNAL EDUKASI: Jurnal Bimbingan Konseling, 1(1), 20-28.

Wangge, B. D., \& Hartini, N. (2013). Hubungan antara penerimaan diri dengan harga diri pada remaja pasca perceraian orangtua. Jurnal Psikologi Kepribadian Dan Sosial, 2(1), 1-6.

Wolters, C. A., Pintrich, P. R., \& Karabenick, S. A. (2005). Assessing academic selfregulated learning. In What do children need to flourish? (pp. 251-270). Springer.

Zimmerman, B. J. (1990). Selfregulated learning and academic achievement: An overview. Educational Psychologist, 25(1), 3-17.

Zimmerman, B. J. (2013). Theories of self-regulated learning and academic achievement: An overview and analysis. In Self-regulated learning and academic achievement (pp. 10-45). Routledge.

Zimmerman, B., \& Schunk, D. (1989). Self-regulated learning and academic: Theory, research, and practice. New York: Springer Verlag. 